\title{
Polyamide Fibers Covered with Chlorhexidine: Thermodynamic Aspects
}

\author{
E. Giménez-Martín ${ }^{*}$, M. López-Andrade², J. A. Moleón-Baca1, M. A. López³ \\ A. Ontiveros-Ortega ${ }^{1}$ \\ ${ }^{1}$ Department of Physics, University of Jaén, Campus Universitario de las Lagunillas, Jaén, Spain \\ ${ }^{2}$ Spanish Dental Council, Madrid, Spain \\ ${ }^{3}$ Odontology Faculty, University of Granada, Granada, Spain \\ Email: ${ }^{*}$ egimenez@ujaen.es
}

Received 24 July 2015; accepted 22 September 2015; published 25 September 2015

Copyright $@ 2015$ by authors and Scientific Research Publishing Inc.

This work is licensed under the Creative Commons Attribution International License (CC BY). http://creativecommons.org/licenses/by/4.0/

(c) (i) Open Access

\section{Abstract}

Results of dynamic and equilibrium of sorption of a reactive dye Remazol Brilliant Blue, and a bactericidal agent, Digluconate of Chlorhexidine over Polyamide fibers are presented with the aim of supplying the fiber with bactericidal properties. However, adsorption of Chlorhexidine onto Polyamide is scarce due to the lack of interactions between the reactive groups of the fiber and the antiseptic molecule. Therefore, in order to provide the fiber surface with anionic groups, fiber has been previously dyed with Remazol Brilliant Blue which increases the negative charge of the fiber surface due to the presence of its sulfonate end groups. Thermodynamic parameters of equilibrium sorption in the two situations, fiber/dye and fiber-dye/Chlorhexidine, have been analyzed, as function of the temperature, $\mathrm{pH}$ and concentration of the dye in the pretreatment. Results show that when sorption of Remazol Brilliant Blue reaches the value of about $50 \mathrm{mmol} /$ $\mathrm{kg}$ at the higher temperature and concentration tested, the amount of Chlorhexidine adsorbed exhibits its maximum value which is $6 \mathrm{mmol} / \mathrm{kg}$. Both processes, adsorption of Remazol Brilliant Blue and adsorption of Chlorhexidine, fit well to Langmuir adsorption model, suggesting the existence of some kinds of specific interactions between adsorbent and adsorbate. Thermodynamic functions show that the interaction is endothermic and spontaneous in all the rage of temperature tested. The kinetic studies show that sorption of Remazol Brilliant Blue is better described by pseudo-first order model, while sorption of Chlorhexidine fits better to pseudo-second order model, and seems to be quicker process. According to the obtained results, chemical interaction between the vinyl-sulfone group of Remazol Brilliant Blue and the amine groups of Polyamide fiber, followed by electrostatic interactions between the guanine group of the Chlorhexidine and the sulfonate group of the dye must be considered in order to explain the adsorption process.

${ }^{*}$ Corresponding author. 


\section{Keywords}

\section{Nylon 6.6, Reactive Dye, Chlorhexidine, Adsorption Isotherms, Kinetic of Adsorption}

\section{Introduction}

Synthetic polymers now constitute one of the most successful and useful classes of materials and possess a broad range of physical properties. Actually the development in polymer industry covers a huge variety of applications ranging from technological to medical issues. Thus, synthetic polymers are being used as semiconductors, as bullet proof vest, in medicine to deliver drugs, or as artificial skin, for many other applications that were not imagined just few years ago. Rapid advances in polymers are enabling the nanotechnology revolution. However, one of the more extensively applied areas of development of polymer science could be health industry, where the application of different polymers as biomaterials and medical device designs has become progressively more complex. As an example, the use of textile fibers provided with pharmaceutical compounds such as antiseptics or antiinflamatory substances, which could be gradually released in a topic surface, is being nowadays one of the main features in textile industry research.

Polyamides fibers are type of synthetic fibers which has recurring amide groups as an integral part of the main polymer chain commonly named as Nylon. DuPont researches (1930s) invented Nylon 6.6 (polyhexamethylene diamine adipamide) a polyamide made from hexamethylenediamine and adipic acid by polycondensation to form a repeating unit of 12 carbon atoms [1]. Shorter hydrogen bonds between the polymer chains line up creating a stronger, tighter, ordered, dense polymer structure [2]. Nylon 6.6 has a number of useful properties due to its semicrystalline structure [3]. They exhibit good chemical tolerance and high hydrophobic behavior [4] [5]. Because of its characteristics, Nylon is probably the most useful synthetic polymer material. It is present in a wide range of different technological uses although one of the most common is textile industry. It is also applied in medicine in a wide range of applications such as surgical instruments, sutures, catheters, coronary stents, pacemakers, gloves and bandages. Because of the mentioned extensive advantages of this polymer in health care as textiles or medical devices, it is essential to avoid adhesion and proliferation of bacteria on the material surface that could induce severe health hazards; hence, polymer surfaces provided with bactericidal and bacteriostatic properties that can prevent attachment, proliferation and survival of microbes in material surface are being extensively required [6].

In previous work we have investigated adsorption and desorption of Chlorhexidine, $\mathrm{CHX}$, to cellulosic fibers in order to supply these fibers with antiseptic properties [7]. CHX has been widely used as an effective antibacterial agent commonly applied as disinfectant to bactericidal agents in dentistry, due to its broad range of antimicrobial activities against bacteria and fungi, high killing rate and nontoxicity toward mammalian cells [8]. However, many materials that include CHX in its presentation need to be plunged in CHX solution that gradually works as antiseptic while the material is wet. To avoid this disadvantage, in the present work our interest is focused in providing polyamide fibers with known concentration of CHX adsorbed onto dry fiber surface, which could supply it with antiseptic properties forming a barrier against further contaminations or releasing the antiseptic topically in required conditions. The main application of the results obtained will be dental material for topic use such as toothbrush, surgical sutures, material for root endodontic treatment [9].

Because of the lack of interactions between amino ends groups of the fiber and the amino groups of the CHX molecules even in slightly acid conditions, in this investigation we have studied the possibility of adsorbing CHX molecules over a Nylon 6.6 previously dyed with a reactive dye, Remazol Brilliant Blue, RBBR. This dye is a kind of vinyl-sulfone reactive dye that forms covalent bonds with amine groups of Nylon fibers at slightly acid $\mathrm{pH}[10]$ [11] providing the fiber surface with negative charge.

The use of surfactants [12], polyelectrolyte [13] [14], or polar compounds [15] to provide different fibers with required reactive groups that could help posterior adsorption of desired substances over different fibers, has been extensively studied by our research group.

In the present situation, the use of the reactive dye RBBR has enabled the subsequent adsorption of the cationic biguanide molecule of CHX. We present here the results of a combined investigation of equilibrium and dy- 
namic of sorption of RBBR onto Nylon 6.6, and of CHX onto Nylon coated previously with RBBR molecules.

\subsection{Equilibrium Models for Adsorption Isotherms}

The Langmuir and Freundlich equations are generally applied as a convenient approach to describe the adsorption process from water solution onto a solid adsorbent as it is textile fibers.

\subsubsection{Langmuir Isotherm}

Langmuir isotherm model assumes that sorption takes place at specific homogeneous sites within an adsorbent where all sorption sites are identical and energetically equivalent and there is no interaction between molecules adsorbed on neighboring sites. Therefore, a saturation value is reached beyond which no further sorption could take place, meaning that once a site is occupied no further adsorption can take place in this site. This theory considers that the adsorbent behaves as an ideal solid surface, where adsorbate can be bonded either by physisorption or chemisorption. Intermolecular forces decrease abruptly with distance and the model predicts only monolayer coverage [16].

The Langmuir model equation is:

$$
q_{e}=\frac{X_{m} a_{L} C_{e}}{1+a_{L} C_{e}}
$$

where $q_{e}$ is the equilibrium concentration of adsorbate per unit weight of dry adsorbent ( $\mathrm{mmol} \cdot \mathrm{kg}^{-1} \mathrm{or} \mathrm{mg} \cdot \mathrm{g}^{-1}$ ); $C_{e}$ is the equilibrium concentration of adsorbate in the solution (mmol $\cdot \mathrm{dm}^{-3}$ or $\mathrm{mg} \cdot \mathrm{dm}^{-3}$ ); $X_{\mathrm{m}}$ is the theoretical monolayer capacity (mmol $\cdot \mathrm{kg}^{-1}$ or $\mathrm{mg} \cdot \mathrm{g}^{-1}$ ) and $a_{L}$ is a constant related to the affinity binding sites $\left(\mathrm{dm}^{3} \cdot \mathrm{mmol}^{-1}\right.$ or $\mathrm{dm}^{3} \cdot \mathrm{mg}^{-1}$ ). Langmuir constant can be defined as $K_{L}=X_{m} a_{L}$. In the present work in order to compare the interaction between molecules of RBBR and molecules of CHX in the adsorption process, every concentration of adsorbate has been expressed as mmol instead of $\mathrm{mg}$.

The constants have been determined from linear fit of Equation (1) in the following form:

$$
\frac{C_{e}}{q_{e}}=\frac{1}{X_{m} a_{L}}+\frac{1}{X_{m}} C_{e}
$$

\subsubsection{Freundlich Isotherm}

This model assumes some modifications of Langmuir model such as surface roughness, inhomogeneity, and adsorbate-adsorbate interactions. It is the most important multisite adsorption isotherm for rough surfaces and this empirical model has been shown to be consistent with exponential distribution of active centers characteristic of heterogeneous surface. The empirical equation is:

$$
q_{e}=K_{F} C_{e}^{\frac{1}{n_{F}}}
$$

where $K_{F}$ is the Freundlich constant $\left(\mathrm{dm}^{3} \cdot \mathrm{mmol}^{-1}\right.$ or $\left.\mathrm{dm}^{3} \cdot \mathrm{mg}^{-1}\right)$ and $1 / n_{F}$ is the heterogeneity factor. If $n>1$, then the adsorption is favorable. From a linear fit of Equation (4), these empirical values were obtained.

$$
\ln q_{e}=\ln K_{F}+\frac{1}{n_{F}} \ln C_{e}
$$

Values of thermodynamic functions could be obtained from thermodynamic sorption curves. The standard free energy of adsorption, $\Delta G^{\circ}$ at a temperature $T$, can be evaluated from the following equation assuming an ideal behavior of the solution:

$$
\left(\Delta G^{o}\right)_{T}=-R T \ln \left[\frac{\frac{q_{e}}{V}}{C}\right]
$$

where the term $\left[\left(\frac{q_{e}}{V}\right) / C\right]=K$ is the process constant, in which $V$ is the specific volume of the fiber $(0.87$ 
- $1.15 \mathrm{dm}^{3} / \mathrm{kg}$ ) data obtained from bibliography [17] and for the calculation has been assumed as $1 \mathrm{dm}^{3} / \mathrm{kg}$.

The changes of the enthalpy of the sorption process, $\Delta H_{a d}^{o}$ can be evaluated at various temperatures intervals by means of the Clausius-Clapeyron equation, whose integrated form is:

$$
\Delta H_{a d}^{o}=\frac{R\left(\ln C_{2}-\ln C_{1}\right) T_{1} T_{2}}{T_{1}-T_{2}}
$$

Such evaluation assumes that the solution behaves as an ideal one and that the heat of dilution is negligible compared with the heat of adsorption, at this low concentration.

The change of entropy, $\Delta S_{\text {ad }}^{o}$ could be determined using the equation:

$$
\Delta S_{a d}^{o}=\frac{R\left(T_{1} \ln C_{1}-T_{2} \ln C_{2}\right)}{T_{1}-T_{2}}
$$

\subsection{Kinetic Models of Sorption Systems}

The knowledge of the reaction rate of sorption of a molecule to a fiber, gives insight about the mechanism involved. In order to investigate the mechanism of sorption, the rate constants of chemical sorption and intraparticle diffusion for the dye RBBR and the polyamine CHX molecule were determined using the equations of pseudo-first order system by Langergren [18], a pseudo-second order and intraparticle diffusion model.

\subsubsection{Pseudo-First Order Model}

$$
\frac{\mathrm{d} q_{t}}{\mathrm{~d} t}=k_{1}\left(q_{e}-q_{t}\right)
$$

Integrating for the boundary conditions $t=0$ to $t=t$ and $q_{t}=0$ to $q_{t}=q_{e}$ gives:

$$
\ln \left(q_{e}-q_{t}\right)=\ln \left(q_{e}\right)-k_{1} t
$$

where $q_{e}$ is the amount of dye sorbed at equilibrium ( $\mathrm{mmol} \cdot \mathrm{kg}^{-1}$ ) or $\left(\mathrm{mg} \cdot \mathrm{g}^{-1}\right) ; q_{t}$ is the amount of dye sorbed at time $t\left(\mathrm{mmol} \cdot \mathrm{kg}^{-1}\right)$ or $\left(\mathrm{mg} \cdot \mathrm{g}^{-1}\right)$ and $k_{1}$ is the equilibrium rate constant of first order sorption $\left(\mathrm{min}^{-1}\right)$. The intercept of the straight line plots of $\ln \left(q_{e}-q_{t}\right)$ against $t$ should equal $\ln \left(q_{e}\right)$. However, if the intercept does not equal $q_{e}$ then the reaction is not likely to be first order reaction, and even this plot has high correlation coefficient with experimental data [19].

\subsubsection{Pseudo-Second Order}

The rate constant is described by:

$$
\frac{\mathrm{d} q_{t}}{\mathrm{~d} t}=k_{1}\left(q_{e}-q_{t}\right)^{2}
$$

Integrating for the boundary conditions $t=0$ to $t=t$ and $q_{t}=0$ to $q_{t}=q_{e}$ gives:

$$
\frac{t}{q_{t}}=\frac{1}{k_{2} q_{e}^{2}}+\frac{1}{q_{e}} t
$$

From the fit of $\frac{t}{q_{t}}$ against $t$ it can be obtained $k_{2}$ and $q_{e}$.

The initial sorption rate $h\left(\mathrm{~g} \cdot \mathrm{mg}^{-1} \cdot \mathrm{min}^{-1}\right)$ or $\left(\mathrm{kg} \cdot \mathrm{mmol}^{-1} \cdot \mathrm{min}^{-1}\right)$ :

$$
h=k q_{e}^{2}
$$

\subsubsection{Diffusion Model}

Fick's equation, should be applied to estimate the approximated diffusion coefficient, $D$, at the cylindrical walls of the fiber 


$$
\frac{q_{t}}{q_{e}}=\frac{4}{\pi^{\frac{1}{2}}}\left(\frac{D t}{a^{2}}\right)^{\frac{1}{2}}
$$

where $a$ is the fiber radio which has been determined with a microscope as $5 \times 10^{-4} \mathrm{~cm}$ in accordance with the value determined by Espinosa-Jiménez [17]. The apparent diffusion coefficient can be obtained plotting $\frac{q_{t}}{q_{e}}$ versus $t^{1 / 2}$ under assumption that the surface concentration is constant.

\section{Experimental}

\subsection{Materials}

\subsubsection{Fiber}

Fibers of Nylon 6.6, used in the present work is $100 \%$ polyamide 6.6 yarn, style 361 , was supplied by Testfabrics (Spain). Its density is about $1 \mathrm{~g} / \mathrm{cm}^{3}$, fusion temperature $250^{\circ} \mathrm{C}$, water absorption $10 \%-20 \%$ when dipped in water and water content is ca. $3.8 \%-4.1 \%$ at $20^{\circ} \mathrm{C}$ and $65 \%$ of relative humidity. The fiber was repeatedly rinsed with deionizer water until water conductivity remained constant, and them they were dried in an oven and stored. Nylon 6.6 structure is represented in Scheme 1.

\subsubsection{Dye}

Reactive dye used in the present work is Remazol Brilliant Blue R (RBBR), Colour Index Number 61,200 Reactive Blue 19) (Scheme 2) was A.R grade was provided by Sigma Company. Its molecular formula is: $\mathrm{C}_{22} \mathrm{H}_{16} \mathrm{~N}_{2} \mathrm{Na}_{2} \mathrm{O}_{11} \mathrm{~S}_{3}$ and has a molecular weight of $626.55 \mathrm{~g} \cdot \mathrm{mol}^{-1}$, and its solutions present a maximum of adsorbance at $593 \mathrm{~nm}$. RBBR structure is depicted in Scheme 2.

\subsubsection{Antiseptic}

The antiseptic used, Chlorhexidine (CHX) is presented as a salt solution, Chlorhexidine Digluconate, with initial concentration $20 \% \mathrm{w} / \mathrm{v}$ aqueous solution, and has been supplied by Dentaid S.A (Spain). Its molecular formula is $\mathrm{C}_{34} \mathrm{H}_{30} \mathrm{~N}_{10.2}\left(\mathrm{C}_{6} \mathrm{H}_{12} \mathrm{O}_{7}\right)$ and has a molecular weight is $897.8 \mathrm{~g} \cdot \mathrm{mol}^{-1}$. The maximum adsorbance of its solutions corresponds to $231 \mathrm{~nm}$. CHX structure is depicted in Scheme 3.

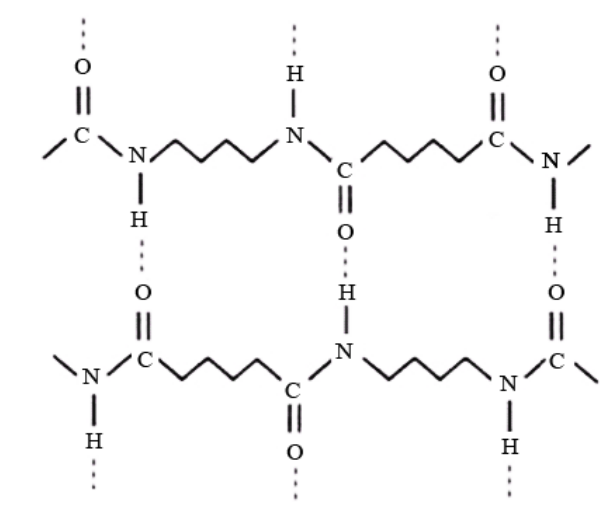

Scheme 1. Nylon 6.6.

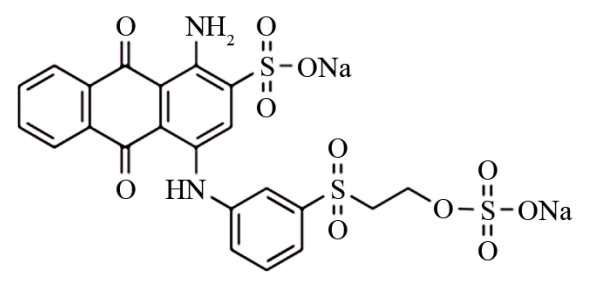

Scheme 2. Remazol brilliant blue R molecule. 


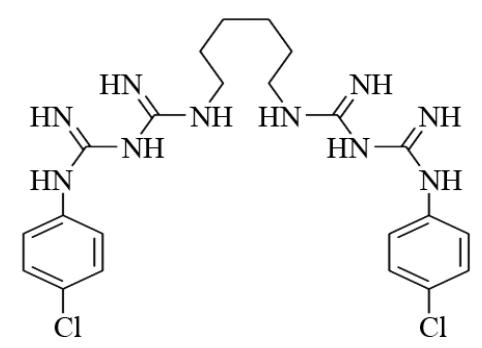

Scheme 3. Chlorhexidine molecule.

\subsection{Methods}

\subsubsection{Sorption Experiments}

Pellets of $1 \mathrm{~g}$ of dried fiber were used for sorption and electrokinetic experiments. The samples were dipped in $100 \mathrm{ml}$ of RBBR or CHX water solutions of different concentration and $\mathrm{pH}$ and temperature conditions were adapted depending on the experiment performed. The sorption was performed in a thermostated water bath (WNB Memmert) with constant stirring and temperature accuracy of $\pm 0.1 \mathrm{~K}$ during 48 hours, time enough to achieve equilibrium. The kinetic determinations were performed in the same way, using $250 \mathrm{ml}$ of initial solution. The amount of adsorbate that has been uptaken by the fiber was determined from the difference between the initial and final concentration of the solution, estimated by optical absorbance at both wavelength $581 \mathrm{~nm}$ for the dye solutions and 231 for CHX solutions, with a Hitachi U-2000 spectrophotometer. The amount of adsorbate uptaken by the fiber has been expressed as mmol $\mathrm{kg}^{-1}$ of dry fiber, and the concentration of solution as $\mathrm{mmol} \cdot \mathrm{l}^{-1}$. Adsorption data isotherms have been analyzed considering Langmuir and Freundlich models, as well as to investigate about kinetics mechanism involved we have tested a pseudo-first order, pseudo- second order an intraparticle diffusion models.

\subsubsection{Zeta Potential Measurements}

The evolution of zeta potential of the fiber plug has been determined by streaming potential method, with Fairbrother-Mastin [20] equation:

$$
\zeta=\frac{\Delta U \cdot \eta \cdot K_{m}}{\Delta p \cdot \varepsilon \cdot \varepsilon_{0}}
$$

where $\Delta U$ streaming potential, $\Delta p$ pressure difference, $K_{m}$ conductivity of the electrolyte solution, $\eta$ dyamic viscosity of electrolyte solution. Zeta potential has been determined by streaming potential with an Electrokinetic Analyzer, EKA (Anton Paar, KG). Samples of $1 \mathrm{~g}$ of fiber were placed between two electrodes at a constant distance of $1 \mathrm{~cm}$ of a cylindrical cell of $20 \mathrm{~mm}$ diameter, which correspond to a bulk sample density in the cell of around 0.35 to $0.40 \mathrm{~g} / \mathrm{cm}^{-3}$. An electrolyte solution of $1 \mathrm{mM} \mathrm{KCl}$ is forced to stream along the solid surface by a pressure difference, and the flow should change its direction periodically. The streaming potential is measured with two electrodes Ag/AgCl placed at both sides of the sample. Tritiation measures were carried out starting at $\mathrm{pH} 10$ and finishing at $\mathrm{pH} 2.5-3$ adjusting $\mathrm{pH}$ with $\mathrm{NaOH}$ or $\mathrm{HCl}$ respectively. Operating temperature should be close to standard room temperature $\left(25^{\circ} \mathrm{C} \pm 3^{\circ} \mathrm{C}\right)$.

\section{Results and Discussion}

\subsection{Dye Adsorption}

\subsubsection{Effect of Initial $\mathrm{pH}$}

Most of dyes present an ionic character in solution being the reactive dye RBBR an anionic one. The sorption of these charged dyes onto the adsorbent surface is primarily influenced by the surface charge on the adsorbent, which in turns is influenced by the solution $\mathrm{pH}$. Thus the knowledge of the electrical potential of the fiber surface as function of the $\mathrm{pH}$ of the medium gives information about the electrostatic interactions that could take place between the dye and the fiber surface. Due to the amphoteric character of the fiber the concentration of the four possible fiber terminal groups, $\mathrm{Ny}-\mathrm{NH}_{2}, \mathrm{Ny}-\mathrm{NH}_{3}^{+}$, $\mathrm{Ny}-\mathrm{COOH}$ AND Ny-COO${ }^{-}$(where $\mathrm{Ny}$-represents the Nylon 6.6 polymer chain) will be determined not only by the concentration of amino or carboxyl terminal group 
but mainly by the $\mathrm{pH}$ of the medium. The equilibrium between the four species depends on the $\mathrm{pH}$ of the medium as follow [21].

$$
\mathrm{NH}_{2}-\mathrm{Ny}-\mathrm{COO}^{-} \stackrel{\mathrm{H}^{+}}{\longleftrightarrow} \mathrm{NH}_{2}-\mathrm{Ny}-\mathrm{COOH} \stackrel{\mathrm{H}^{+}}{\longleftrightarrow} \mathrm{NH}_{3}^{+}-\mathrm{Ny}-\mathrm{COOH}
$$

In order to know the charge of the fiber surface, in Figure 1 is presented the evolution of the zeta potential of Nylon 6.6 as function of the $\mathrm{pH}$ of aqueous medium and $1 \mathrm{mM} \mathrm{NaCl}$ solution. The similarity in the evolution of zeta potential indicates that $\mathrm{NaCl}$ behaves as an indifferent electrolyte for Nylon 6.6 fibers.

As it can be observed, Nylon 6.6 is highly influenced by the $\mathrm{pH}$ of the medium. After the fiber is immersed in an ionic medium the presence of $\mathrm{H}^{+}$or $\mathrm{OH}^{-}$should be responsible of the ionization to a greater or lesser extend of the amino and carboxylic acid groups of the fiber. An isoelectric point, IP, is presented at $\mathrm{pH}$ ranging from 4 to 4.5 in water and $1 \mathrm{mM} \mathrm{NaCl}$ solution respectively. Espinosa et al., [18] using a microelectrophoretic technique for zeta potential determination, have obtained a value of 3.5 units $\mathrm{pH}$. The difference could be due to some alteration in the number of polar groups onto the fiber surface causes by morphological changes in fiber structure due to the samples treatment. The zeta potential of the fiber is negative for $\mathrm{pH}$ higher than $4-4.5$ units and it increases up to ca $-50 \mathrm{mV}$ for $\mathrm{pH} 10$. From $\mathrm{pH}$ below 4, the fiber presents positive charge. The change in the sign of zeta potential from an IP depends on the ionization of both amine and carboxylic groups. At pH lower than 4 units, ionization of $\mathrm{NH}_{3}^{+}$prevails on the $\mathrm{COOH}$ one, while for $\mathrm{pH}$ above IP, $\mathrm{COO}^{-}$is the most important one. Nevertheless, at both very acidic and highly alkaline $\mathrm{pH}, \zeta$ is determined by adsorption of $\mathrm{H}^{+}$and $\mathrm{OH}^{-}$ions in the double layer.

The influence of the $\mathrm{pH}$ of the medium in the adsorption of RBBR is presented in Figure 2 where it is shown

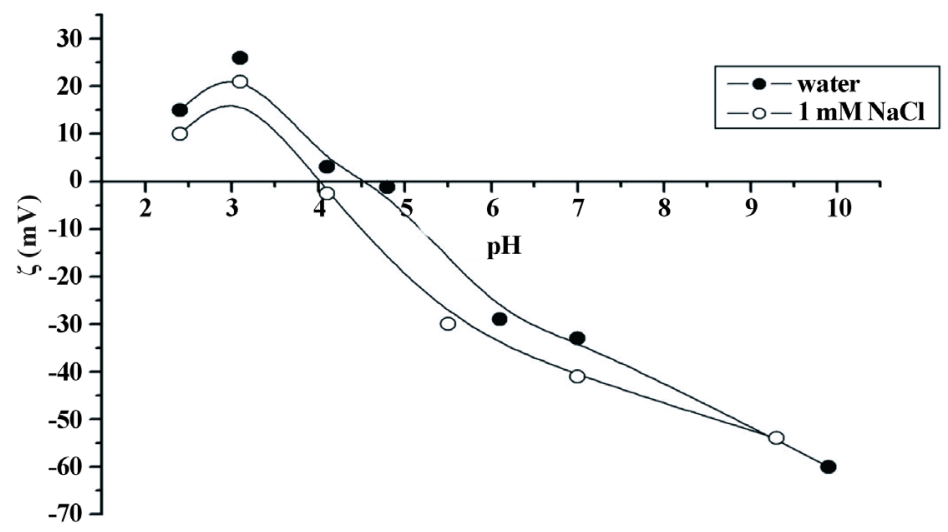

Figure 1. Zeta potential of Nylon 6.6 as function of $\mathrm{pH}$ of aqueous and $\mathrm{NaCl} 1 \mathrm{mM}$ medium.

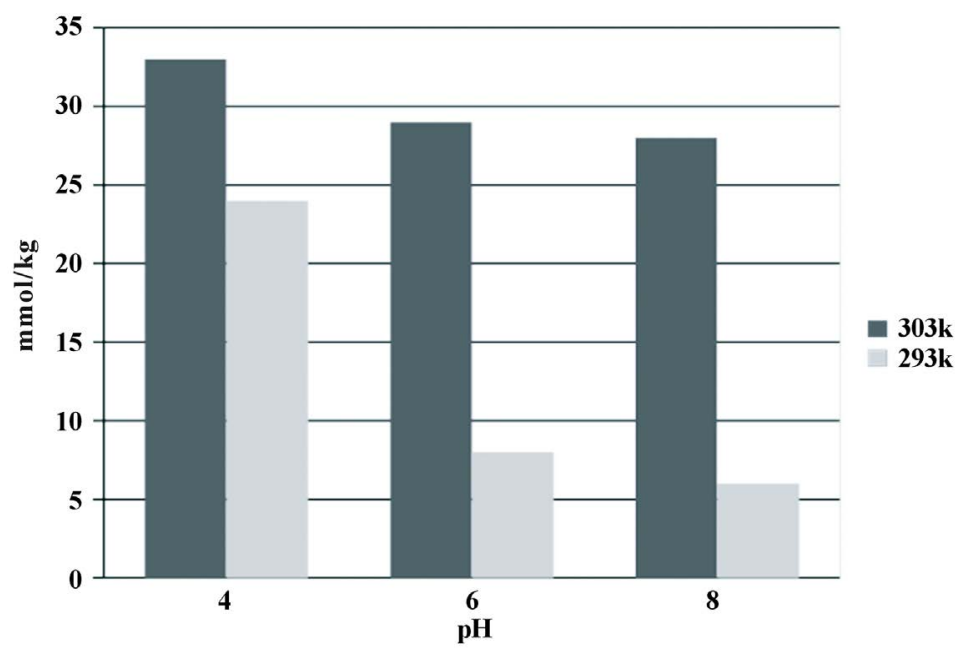

Figure 2. Amount of RBBR uptaken by Nylon 6.6 as function of the $\mathrm{pH}$ and of the temperature. 
the amount of dye adsorbed, in $\mathrm{mmol} \cdot \mathrm{kg}^{-1}$ of dried fiber, for an initial concentration of the treatment of $0.5 \mathrm{mM}$ of RBBR at two different temperature $303 \mathrm{~K}$ and $293 \mathrm{~K}$. As it can be seen the maximum absorption takes place at the lowest $\mathrm{pH}, \mathrm{pH} \mathrm{4}$, and at the highest temperature tested. It is also relevant to realize, that the influence of the $\mathrm{pH}$ is much accurate at the lower temperature tested. In our opinion, as chemical interactions takes place at high temperature, in this situation, two mechanisms would be responsible of sorption process. Besides covalent bonding between vinyl sulfone group of RBBR and amine group of the fiber [22], we must consider electrostatic interactions between ionized amino group, $\mathrm{NH}_{3}^{+}$and the sulfonate terminal of $\mathrm{RBBR}, \mathrm{SO}_{3}^{-}$. But at higher $\mathrm{pH}$, when the fiber presents negative charge on its surface, the lack of this last mechanism will justified the drop in the amount of RBBR uptaken by the fiber. At low temperature chemical interactions diminish, and this situation besides electrostatic repulsion give rises to the scarce adsorption observed at high $\mathrm{pH}$ and low temperature.

\subsubsection{Adsorption Isotherms}

The results of adsorption of RBBR onto Nylon 6.6 at four different temperatures and at natural $\mathrm{pH}$ of solution that is about 6 units $\mathrm{pH}$, are plotted in Figure 3.

As it can be observed sorption rises abruptly with temperature, being its value low and almost constant at low temperature, which is $293 \mathrm{~K}$ and $303 \mathrm{~K}$. For temperature higher than this last one, there is an abrupt increase in the amount adsorbed, and it seems, because of the sharp of the curve, that at the highest temperature no saturation is reached in the conditions tested. The effect of the initial concentration is more pronounced the higher the temperature is. As we have point before, some reactive dyes, can be covalently fixed to Nylon because of the covalent bonds formed between the amino group of the fiber and the vinyl sulfone group of the dye, being the adsorption of dye by polyamide fibers highly influenced by temperature under transition temperature that is about $90^{\circ} \mathrm{C}$. As many researchers have observed [13] [22] [23] working with reactive dyes, initial dye uptake increases with temperature, and the influence of it is much marked at low $\mathrm{pH}$, Figure 2, as we have just observed.

Thermodynamic data have been fitted to Langmuir and Freundlich theoretical model of adsorption. The results are depicted in Figure 4.

The evolution of the data obtained is similar to that presented by Ho and Mc. Kay working with Basic Blue 69 onto peat [23]. The values of $X_{m}$ and $K_{L}$ are favored by temperature, correlation coefficient keeps higher than 0.9 in all the range tested. The values of the theoretical monolayer capacity $X_{m}\left(\mathrm{mmol} \cdot \mathrm{kg}^{-1}\right)$ obtained from Langmuir model present good correlation with experimental data presented in Figure 3. This result seems to point to specific chemisorptions of dye onto the fiber and monolayer distribution.

In order to complete this information thermodynamic functions in the same conditions have been tested. The Standard Free Energy of sorption process obtained from Equation (5), $\Delta G^{0}$ is negative and increases its absolute value with temperature. These results confirm that the process is spontaneous, and favored by temperature. Furthermore, the change in Heat of Adsorption $\Delta H^{0}$, Equation (6), determined at different intervals of temperature is always positive because the reaction is endothermic and temperature favors the process. As Minguand

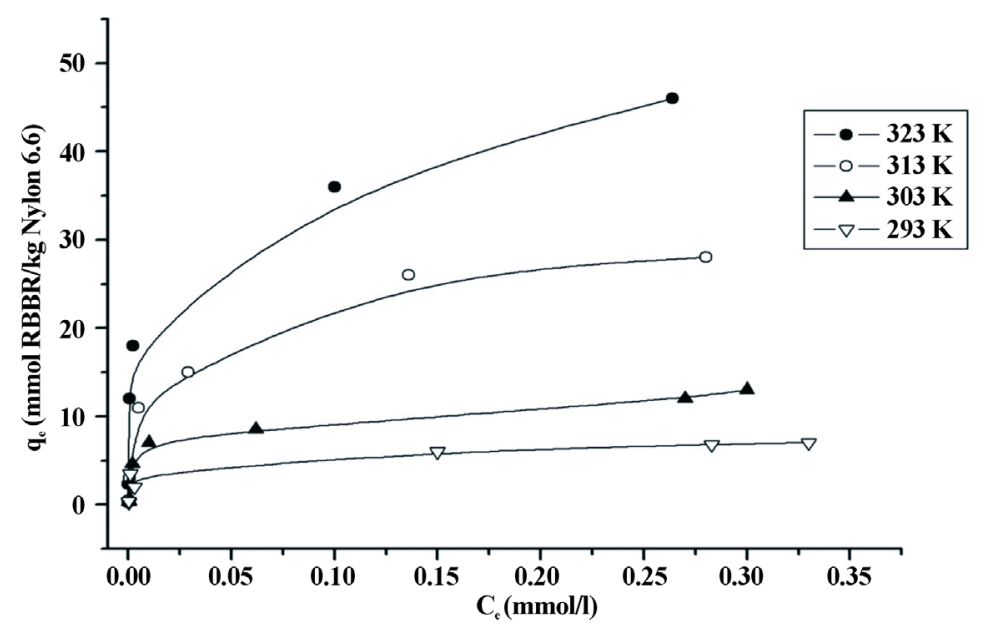

Figure 3. Adsorption isotherms of RBBR onto Nylon 6.6 at different temperatures. 


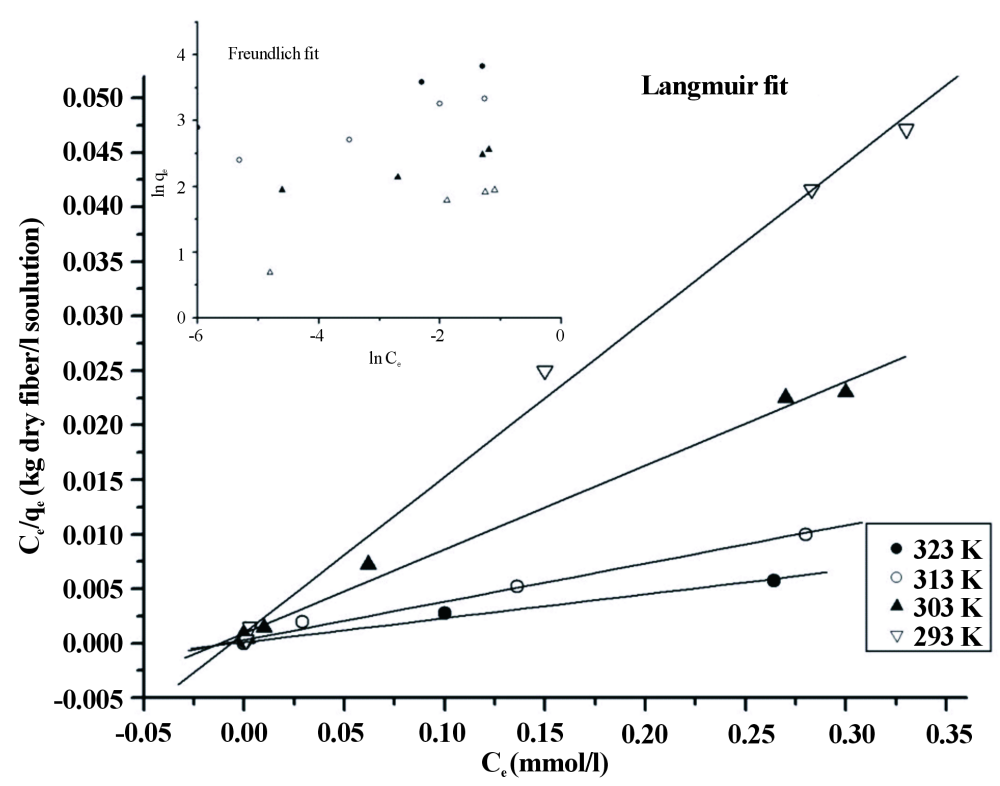

Figure 4. Linear fit of sorption data from Figure 3 to Langmuir and Freundlich models.

suggested [11], when dyeing activated carbon with cationic dyes, the electrostatic repulsion weakens the adsorption forces and then heat is necessary for it to take place. Finally the negative value of change of Entropy $\Delta S^{0}$, Equation (7) seems to suggest a formation of ordered structures. As it could be appreciated in Figure 4, there is no possibility of fitting data to Freundlich model and therefore only Langmuir constant values were presented in Table 1.

\subsubsection{Kinetic of Adsorption}

The results of the kinetic experiences carried out at two temperatures are represented in Figure 5. These experiments have been performed with $1 \mathrm{~g}$ of clean and dry fiber and $250 \mathrm{ml}$ of $0.5 \mathrm{mM}$ RBBR as initial concentration of dye solution. Kinetic data have been fitted to pseudo-first order, pseudo-second order and diffusion model. Results are depicted respectively in Figure 6, Figure 7 and Figure 8, besides, in Table 2 there are listed the kinetic parameters.

Although correlation coefficient, $\mathrm{R}^{2}$, of both, first and second order are high, the calculated $q_{e}$ (amount adsorbed at equilibrium) values obtained for the first-order kinetic model are very similar to the experimental ones. In Table 2 is observed that the rate constant, $k_{1}$, as well as the amount adsorbed at equilibrium, $q_{e}$, increases with temperature. As Espinosa and cols. [17] have observed with Acid Blue 45 over Nylon 6.6, it can be observed that for the first stage of adsorption (up to $100 \mathrm{~min}$ ) the process seems to respond to first order kinetic model.

Furthermore, when comparing the Langmuir results in Table 1 with equilibrium sorption capacity obtained from the kinetic analysis, it is possible to appreciate that at least at high temperature values are very similar, that is, $\mathrm{Xm}=46.10 \mathrm{mmol} \cdot \mathrm{kg}^{-1}$ and $q_{e 1}=49.77 \mathrm{mmol} \cdot \mathrm{kg}^{-1}$ even they are similar to the experimental one that is 50.40 $\mathrm{mmol} \cdot \mathrm{kg}^{-1}$. These observations can reveal that the reaction could be considered pseudo-first order.

Determination of the activation energy $E^{*}$ of dye sorption process evaluated form the equation of Arrhenius-type:

$$
k=A \cdot \mathrm{e}^{-\left(\frac{E^{*}}{R T}\right)}
$$

gives rise to a value of $30.10 \mathrm{~kJ} \cdot \mathrm{mol}^{-1}$, that means that the process needs from temperature to take place although the results are slightly significant because the fit has been done only with two points.

Fitting kinetics data to Fick equation in the form mentioned above, lead us to determination of the apparent diffusion coefficients which are listed in Table 2 . This equation follows a model that is only valid when adsorption takes place with constant concentration of the adsorbate in the adsorbent surfaces and therefore the results 


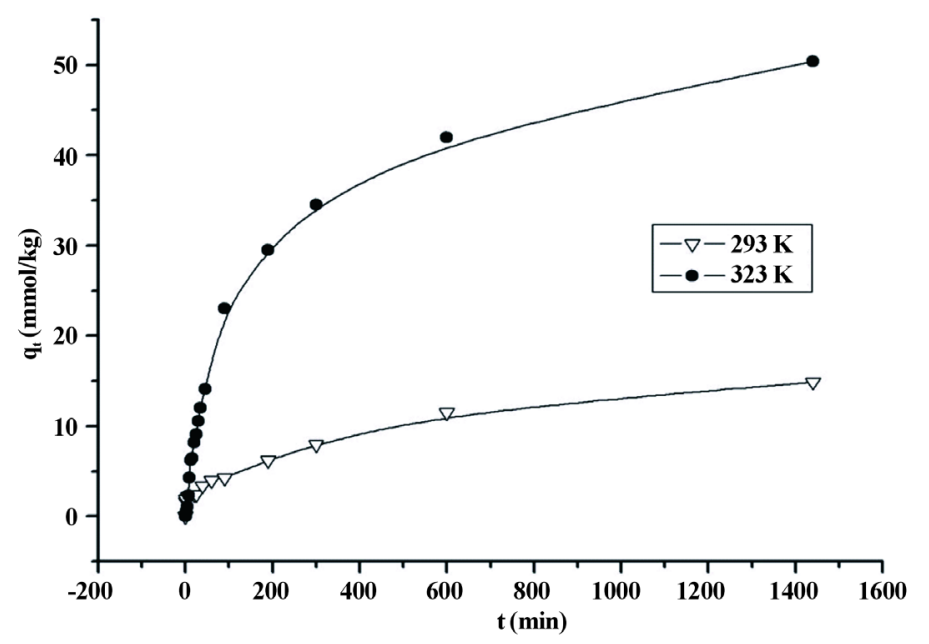

Figure 5. Time-sorption isotherms of Nylon 6.6 dyed with $0.5 \mathrm{mM}$ of RBBR.

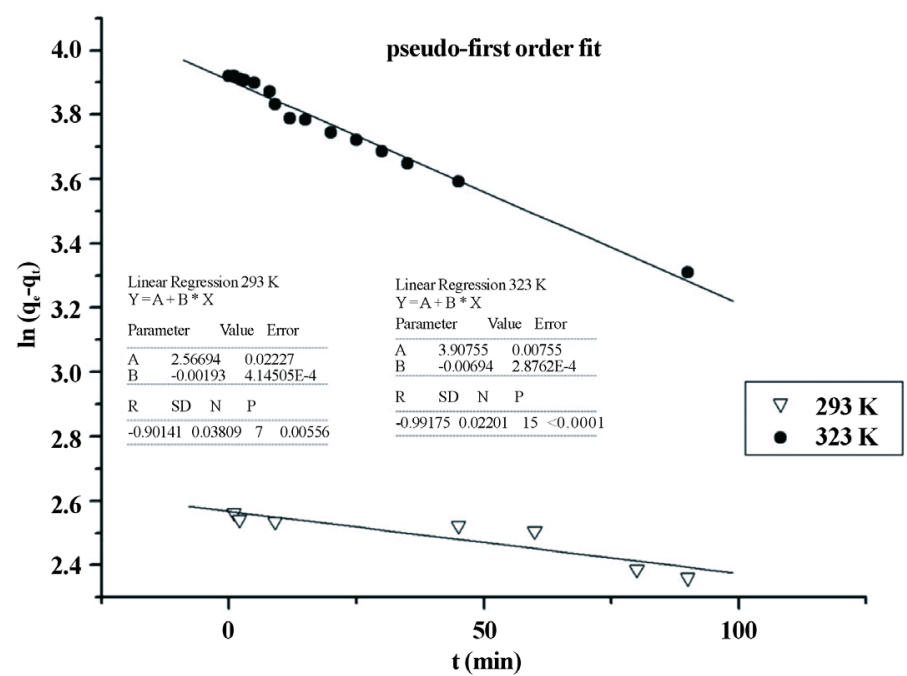

Figure 6. Pseudo-first order model fit of data from time-sorption isotherms of Nylon 6.6 dyed with $0.5 \mathrm{mM}$ of RBBR.

Table 1. Langmuir constants and thermodynamic functions for sorption of RBBR onto Nylon 6.6 as function of temperature.

\begin{tabular}{cccccccccc}
\hline$T$ & $\begin{array}{c}K_{L} \\
\mathrm{l} \cdot \mathrm{kg}^{-1}\end{array}$ & $\begin{array}{c}X_{M} \\
\mathrm{mmol} \cdot \mathrm{kg}^{-1}\end{array}$ & $\begin{array}{c}C_{e} \\
\mathrm{mmol} \cdot \mathrm{l}^{-1}\end{array}$ & $\begin{array}{c}a_{L} \\
\mathrm{l} \cdot \mathrm{mmol}^{-1}\end{array}$ & $R^{2}$ & $\begin{array}{c}\Delta G^{0} \\
\mathrm{~kJ} \cdot \mathrm{mol}^{-1}\end{array}$ & $\begin{array}{c}\Delta T \\
\mathrm{~K}\end{array}$ & $\begin{array}{c}\Delta H^{0} \\
\mathrm{~kJ} \cdot \mathrm{mol}^{-1}\end{array}$ & $\begin{array}{c}\Delta S^{0} \\
\mathrm{~J} \cdot \mathrm{mol}^{-1} \cdot \mathrm{K}^{-1}\end{array}$ \\
\hline 323 & 9238.4 & 45.45 & 0.263 & 203.28 & 0.989 & -13.84 & $323-303$ & 5.131 & -27.00 \\
313 & 3138.4 & 28.50 & 0.283 & 110.12 & 0.993 & -12.01 & $323-293$ & 5.960 & -29.57 \\
303 & 1089.5 & 12.99 & 0.298 & 83.89 & 0.993 & -9.51 & $313-303$ & 4.018 & -23.33 \\
293 & 1062.1 & 6.97 & 0.329 & 152.49 & 0.996 & -7.43 & $313-293$ & 5.798 & -29.01 \\
\hline
\end{tabular}

discussed are only relatives. The values obtained are similar to those from Espinosa-Jiménez [12] and we can point that diffusion is favored by temperature. In this situation, the value of the activation energy $E^{*}$ for the diffusion process is $34.36 \mathrm{~kJ} \cdot \mathrm{mol}^{-1}$, being this value quite similar to that obtained from adsorption process.

\subsection{Antiseptic Sorption}

As it has been mentioned in the introduction section, the aim of the present research is to preparer fibers with 


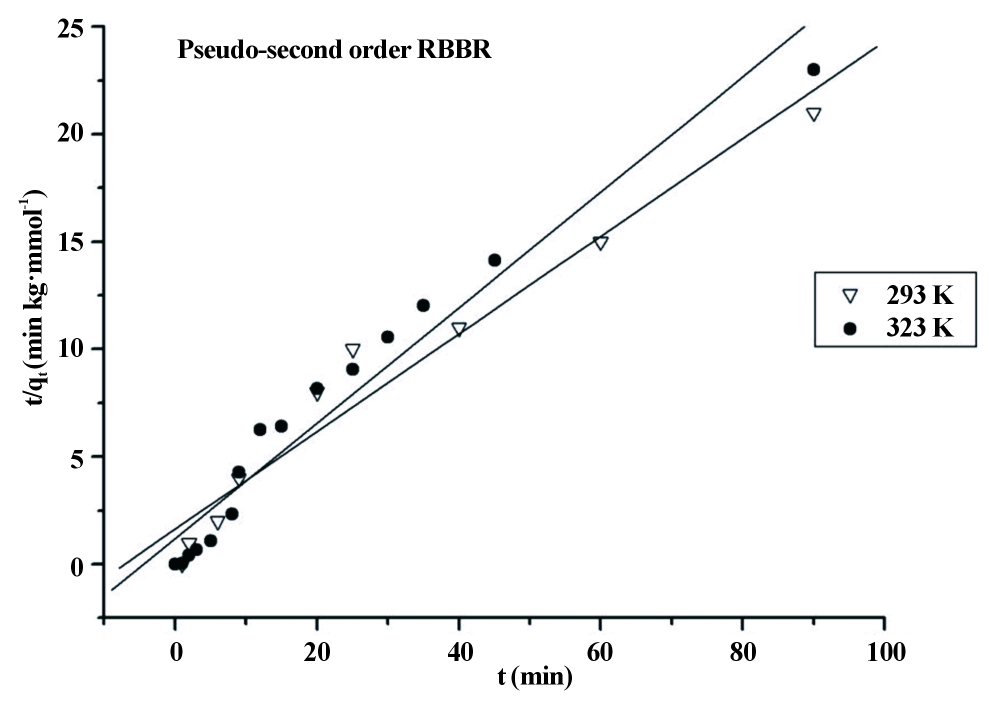

Figure 7. Pseudo-second order model fit of data from time-sorption isotherms of Nylon 6.6 dyed with $0.5 \mathrm{mM}$ of RBBR.

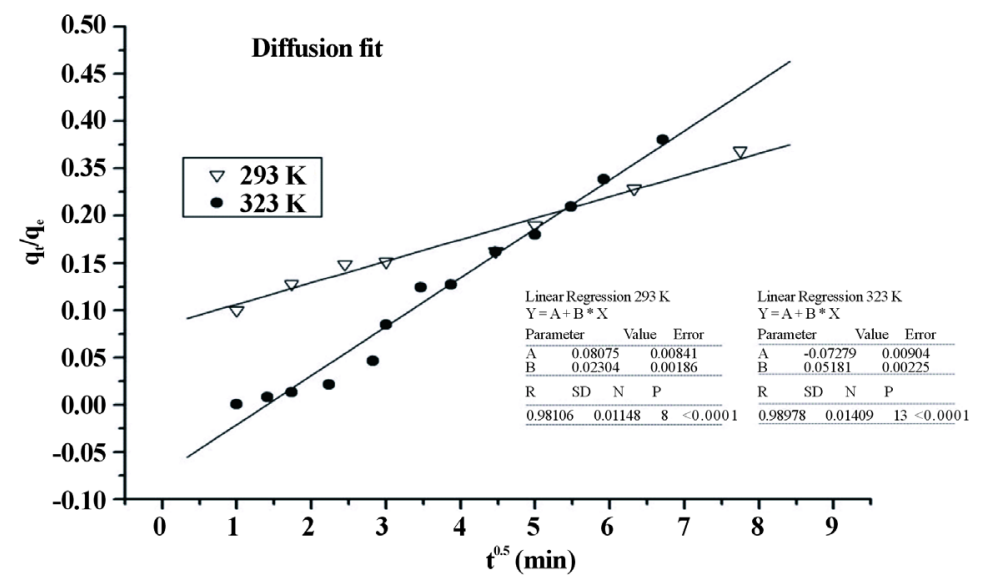

Figure 8. Diffusion model fit of data from time-sorption isotherms of Nylon 6.6 dyed with $0.5 \mathrm{mM}$ of RBBR.

Table 2. Kinetic data for fitting to pseudo-first order, pseudo-second order and diffusion model of sorption of RBBR onto Nylon 6.6 as function of temperature.

\begin{tabular}{|c|c|c|c|c|c|c|c|c|c|c|c|}
\hline \multicolumn{12}{|c|}{ Treatment, 0.5 mM RBBR } \\
\hline \multirow{2}{*}{$\begin{array}{l}T \\
K\end{array}$} & \multirow{2}{*}{$\underset{\substack{\boldsymbol{q}_{\boldsymbol{e}} \\
\text { experimental } \\
\mathrm{mmol} \cdot \mathrm{kg}^{-1}}}{ }$} & \multicolumn{4}{|c|}{ Pseudo-first order model } & \multicolumn{4}{|c|}{ Pseudo-second order model } & \multicolumn{2}{|c|}{ Diffusion } \\
\hline & & $R^{2}$ & $\begin{array}{c}k_{1} \times 10^{3} \\
\min ^{-1}\end{array}$ & $\begin{array}{c}t_{1 / 2} \\
\min \end{array}$ & $\begin{array}{c}q_{e} \\
\mathrm{mmol} \cdot \mathrm{kg}^{-1}\end{array}$ & $R^{2}$ & $\begin{array}{c}k_{2} \times 10^{3} \\
\min ^{-1}\end{array}$ & $\begin{array}{c}t_{1 / 2} \\
\min \end{array}$ & $\begin{array}{c}q_{e} \\
\mathrm{mmol} \cdot \mathrm{kg}^{-1}\end{array}$ & $R^{2}$ & $\begin{array}{l}\mathrm{D} \times 10^{12} \\
\mathrm{~cm}^{2} \cdot \mathrm{s}^{-1}\end{array}$ \\
\hline 293 & 14.87 & 0.988 & 2.32 & 431.03 & 13.44 & 0.986 & 6.296 & 110.1 & 1.98 & 0.976 & 0.59 \\
\hline 323 & 50.40 & 0.983 & 6.94 & 144.09 & 49.77 & 0.985 & 7.12 & 97.35 & 3.16 & 0.979 & 2.18 \\
\hline
\end{tabular}

bactericidal properties, using Chlorhexidine, $\mathrm{CHX}$, as a bactericidal agent. Adhesion and proliferation of bacteria onto material surface is very common and therefore dangerous for its health or technological applications. Unluckily, the previous assays that have been done using Nylon fibers as adsorbent and CHX as adsorbate, have revealed that there is no adsorption at any $\mathrm{pH}$ or temperature tested. Nevertheless, when it is used the system Nylon 6.6-RBBR as adsorbent, adsorption of CHX is possible. Thus, in the present section we shall expose the results of adsorption of CHX over Nylon 6.6 previously treated with RBBR. 


\subsubsection{Adsorption Isotherms}

Sorption experiments of CHX over Nylon 6.6-RBBR system have been carried out, considering initial conditions of $\mathrm{pH}$, temperature and concentration of the pretreatment of the fiber. The $\mathrm{pH}$ of the $\mathrm{CHX}$ aqueous medium has been kept between the interval 6.5 - 7, that correspond to the $\mathrm{pH}$ of $\mathrm{CHX}$ solutions as function of its concentration, because if it diminishes from this value the protonation of the terminal groups of the fiber could hinder the posterior adsorption of the amino groups of CHX. Besides, the competition between the amino groups of the fiber and the amino groups of the CHX molecule for the anionic RBBR molecule, leads to a release of the dye by the fiber, and the solution gets slightly blue. This effect is more pronounced the more acid the CHX solution is. This undesirable situation has been observed in other circumstances. Because of its importance we will describe it here.

When adsorption of CHX as function of temperature is analyzed, we have observed that at low temperature, and low initial concentration of CHX solution, desorption of dye molecules takes place. This effect is more noticeable the lower the concentration and the lower temperature is, as we have been able to verify by measuring RBBR concentration in supernatants solution, although the previously adsorption of dye has been carried at the optimum conditions tested ( $50 \mathrm{mmol} \cdot \mathrm{kg}^{-1}$ of RBBR over the dry fiber). When the fiber is previously treated with low concentration of dye, desorption is then not observed. From this observation we can infer that there could be described two possibility of sorption of dye onto the fiber, a strongly one possible due to chemical interactions and another one that leads to a weaker linkage fiber-dye molecule, maybe electrostatic interactions. The molecules adsorbed by this last mechanism would be the ones first desorbed in less favored sorption requirements for the reactive dye. In Figure 9, it is represented the amount of CHX adsorbed (mmol $\mathrm{kg}^{-1}$ ) at equilibrium as function of final CHX concentration solution, at three temperatures and at constant concentration of the pretreatment of $0.5 \mathrm{mM}$ RBBR. It can be notice that the temperature favored the process and that a low temperature the amount adsorbed is scarce.

Results of the fitting of the adsorption data from Figure 9 Langmuir isotherms models, besides the values obtained for thermodynamic functions are shown in Table 3. As linear fits to Freudlich model exhibits lower correlation coefficients, in the following section only Langmuir results will be analyzed.

Negative value of $\Delta G^{0}$ which exhibits a small increase for a slight raise in temperature from 293 to 313 or 323, indicates that the process is spontaneous. Besides, it could be observed that the process is more endothermic the higher the temperature of the interval tested is, however, the values obtained are lower than those for RBBR sorption listed in Table 1. Finally, values of $\Delta S^{0}$ are negatives and similar to those obtained for sorption of

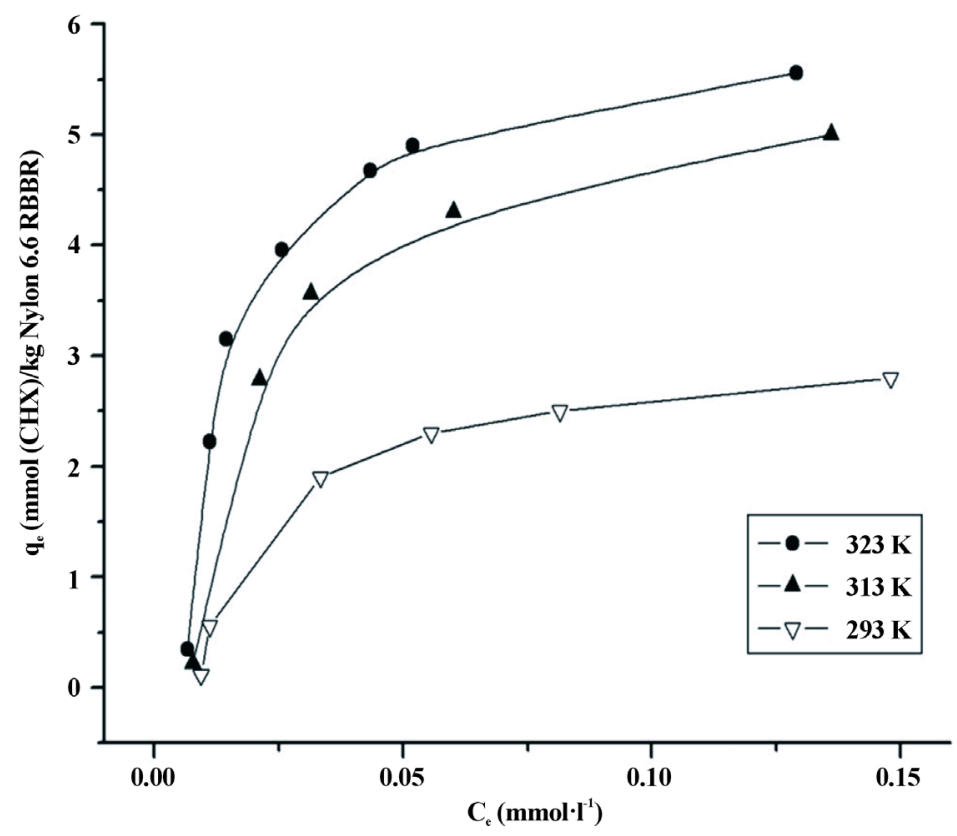

Figure 9. Isotherms of sorption of CHX onto Nylon 6.6 pretreated with 0.5 $\mathrm{mM}$ of RBBR at different temperatures. 
Table 3. Langmuir constants and thermodynamic functions for sorption of CHX onto Nylon 6.6 pretreated with 0.5 mM of RBBR at $323 \mathrm{~K}$, as function of temperature.

\begin{tabular}{ccccccccccc}
\hline$T$ & $\begin{array}{c}K_{L} \\
\mathrm{~K}\end{array}$ & $\begin{array}{c}X_{M} \cdot \mathrm{kg}^{-1} \\
\mathrm{mmol} \cdot \mathrm{kg}^{-1}\end{array}$ & $\begin{array}{c}C_{e} \\
\mathrm{mmol} \cdot \mathrm{l}^{-1}\end{array}$ & $\begin{array}{c}a_{L} \\
\mathrm{l} \cdot \mathrm{mmol}^{-1}\end{array}$ & $\begin{array}{c}\mathrm{X}_{\mathrm{MCHX}} / \mathrm{X}_{\mathrm{MRBBR}} \\
\%\end{array}$ & $R^{2}$ & $\begin{array}{c}\Delta G^{0} \\
\mathrm{kJmol}^{-1}\end{array}$ & $\begin{array}{c}\Delta T \\
\mathrm{~K}\end{array}$ & $\begin{array}{c}\Delta H^{0} \\
\mathrm{~kJ} \cdot \mathrm{mol}^{-1}\end{array}$ & $\begin{array}{c}\Delta S^{0} \\
\mathrm{~J} \cdot \mathrm{mol}^{-1} \cdot \mathrm{K}^{-1}\end{array}$ \\
\hline 323 & 370.37 & 5.6 & 0.129 & 73.67 & 12.32 & 0.999 & -10.13 & $323-313$ & 4.442 & -30.77 \\
313 & 276.24 & 5.2 & 0.136 & 47.63 & 11.44 & 0.999 & -9.38 & $323-293$ & 3.426 & -27.63 \\
293 & 141.64 & 2.9 & 0.147 & 43.71 & 6.38 & 0.999 & -7.09 & $013-293$ & 2.965 & -26.06 \\
\hline
\end{tabular}

RBBR, in our opinion the influence of CXH in the structure of the adsorbent surface is very little. Values of Langmuir parameters obtained from adsorption data of Figure 9 listed in Table 3 shown that in this situation the influence of temperature is only appreciated for the lower one, although a slight increase of Langmuir constant, $K_{L}$, adsorption capacity, $X_{M}$, and $a_{L}$ can be observed, however these values are lower than those of RBBR. We have also estimated the proportion of adsorption capacity of CHX respect of that of RBBR used in the pretreatment as function of the temperature of CHX adsorption, and it is remarkable that the value at $293 \mathrm{~K}$ represents half the value obtained at $323 \mathrm{~K}$.

The influence that the RBBR concentration used in the pretreatment of the fiber exerts in the posterior adsorption of CHX is presented in Figure 10. Experiments have been performed at the higher temperature tested, 323K. It is possible to realize that at low concentration of RBBR in the pretreatment, the amount of CHX adsorbed is low, and this value experiments a marked increase for higher concentration of the pretreatment.

\subsubsection{Kinetic of Adsorption}

Dynamic parameters of the adsorption of $0.5 \mathrm{mM}$ of CHX over Nylon pretreated with $0.5 \mathrm{mM}$ of RBBR at 323 $\mathrm{K}$, as function of two temperatures, have been determined following the same methods as has been done previously for the uptaken of RBBR over the fiber. The results are plotted in Figure 11 as well as in Figure 12 and Figure 13. The kinetic data obtained are shown in Table 4, these data are important in order to obtain information about the reaction involved in the process.

In this situation correlation coefficients for the pseudo-second order fitting, are higher than those of first order. Else, the coincidence between $q_{e}$ values from pseudo-second order and the experimental ones are slightly higher. This fact could point to an activated sorption mechanism characteristic of chemical interaction, as has been suggested by Ho and Mc Kay [23]. Finally the fitting of data to diffusion model gives a low correlation coefficient possible because the linkage of the molecules to the surface avoids the diffusion of CHX into the fiber. Nevertheless the order of magnitude of the diffusion coefficient is similar to the one obtained by Espinosa-Jiménez, and cols. working with Nylon 6.6 [17]. Also, in this situation we appreciate that this factor increases with temperature.

\section{Conclusions}

In the present work, study of the possibility of obtaining polyamide fibers coated with Chlorhexidine is presented. As adsorption of CHX over polyamide fibers is scarce in any experimental conditions tested, it has been necessary to supply fiber surface with suitable chemical groups that could interact with the cationic part of the molecule of CHX.

As we have just presented in this study, the reactive dye Remazol Brilliant Blue can be used for this porpoise because it can interact with both, the amine groups of the polymer and the cationic group of the antiseptic CHX.

As we have observed, adsorption of RBBR follows Langmuir adsorption model and the values of theoretical monolayer capacity, $X_{m}$, and Langmuir constant $\mathrm{K}_{\mathrm{L}}$ at the higher temperature tested are significant, suggesting that specific chemisorptions could be responsible for dye uptaken. In our opinion, adsorption is due to chemical interaction between vinyl-sulfone group of dye and amine groups of polyamide fibers.

Further adsorption of CHX over fiber previously treated is observed, and experimental data suggest, ageing Langmuir adsorption process. In this situation, both concentrations of the pretreatment and temperature, influence further CHX adsorption, although results presented point that the predominant factor is the amount of RBBR preadsorbed over the fiber surface. This fact could point to weaker interactions adsorbent, polyamide-RBBR adsorbate, and CHX molecules. Kinetic studies show that sorption of RBBR is better described by pseudo-first 


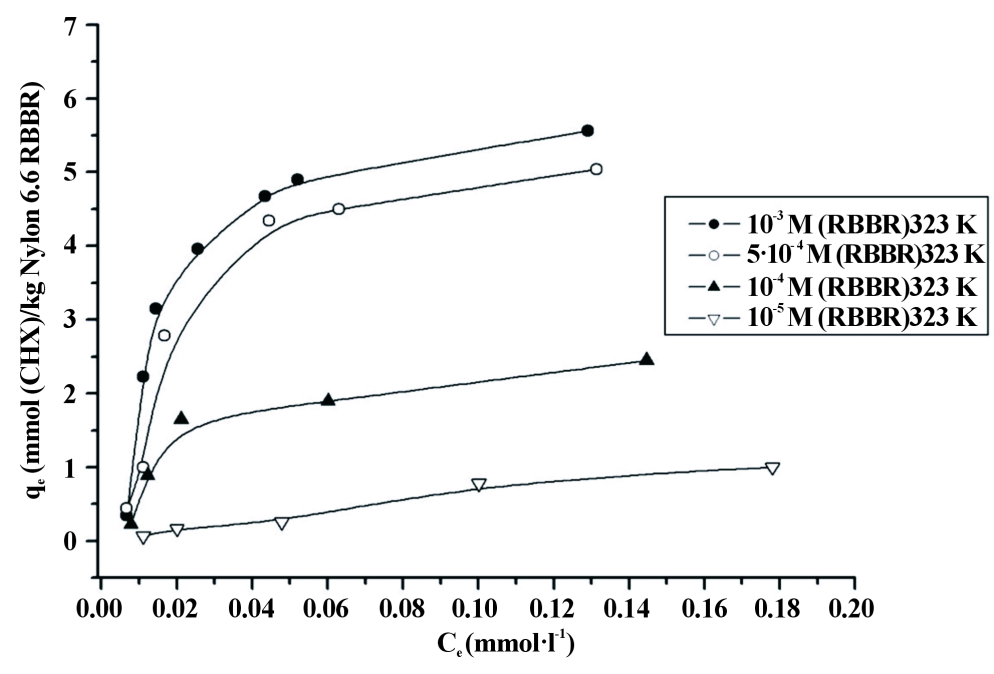

Figure 10. Isotherms of sorption of CHX onto Nylon 6.6 pretreated with $\mathrm{RBBR}$ at $323 \mathrm{~K}$ as function of the concentration of the pretreatment.

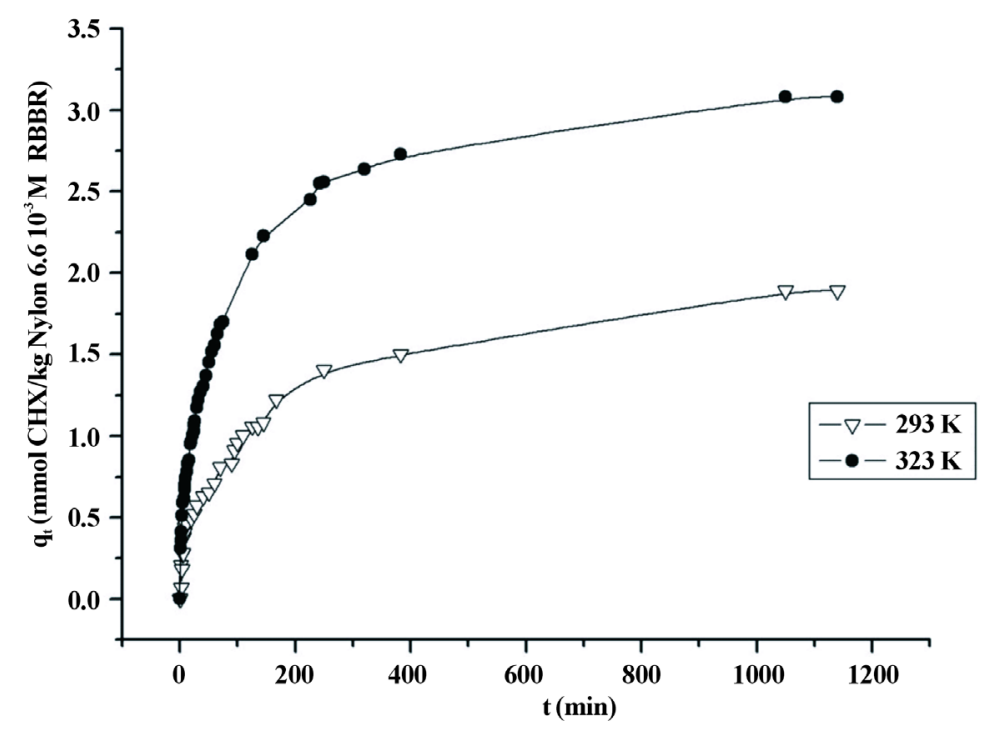

Figure 11. Time-sorption isotherms of adsorption of $0.5 \mathrm{mM}$ CHX over Nylon 6.6 dyed with $0.5 \mathrm{mM}$ of RBBR at $323 \mathrm{~K}$, as function of the temperature.

Table 4. Kinetic parameters of fitting to pseudo-first order, pseudo-second order and diffusion model of sorption of $0.5 \mathrm{mM}$ of CHX onto Nylon 6.6 pretreated with $0.5 \mathrm{mM}$ RBBR as function of temperature.

\begin{tabular}{|c|c|c|c|c|c|c|c|c|c|c|c|}
\hline \multicolumn{12}{|c|}{ Treatment $0.5 \mathrm{mM}$ of RBBR at $323 \mathrm{~K}$, CHX $0.5 \mathrm{mM}$} \\
\hline \multirow[b]{2}{*}{$\begin{array}{c}T \text { K } \\
\text { CHX }\end{array}$} & \multirow[b]{2}{*}{$\begin{array}{c}\boldsymbol{q}_{e} \\
\text { experimental } \\
\mathrm{mmol} \cdot \mathrm{kg}^{-1}\end{array}$} & \multicolumn{4}{|c|}{ Pseudo-first order model } & \multicolumn{4}{|c|}{ Pseudo-second order model } & \multicolumn{2}{|c|}{ Diffusion } \\
\hline & & $R^{2}$ & $\begin{array}{c}k_{1} \times 10^{3} \\
\min ^{-1}\end{array}$ & $\begin{array}{c}t_{1 / 2} \\
\min \end{array}$ & $\begin{array}{c}q_{e} \\
\mathrm{mmol} \cdot \mathrm{kg}^{-1}\end{array}$ & $R^{2}$ & $\begin{array}{c}K_{2} \times 10^{3} \\
\min ^{-1}\end{array}$ & $\begin{array}{c}t_{1 / 2} \\
\min \end{array}$ & $\begin{array}{c}q_{e} \\
\mathrm{mmol} \cdot \mathrm{kg}^{-1}\end{array}$ & $R^{2}$ & $\begin{array}{l}D \times 10^{12} \\
\mathrm{~cm}^{2} \cdot \mathrm{s}^{-1}\end{array}$ \\
\hline 293 & 1.89 & 0.931 & 5.74 & 174.21 & 1.66 & 0.986 & 6.34 & 157.97 & 1.98 & 0.952 & 47.28 \\
\hline 323 & 3.08 & 0.962 & 9.54 & 105.15 & 2.59 & 0.995 & 7.13 & 140.25 & 3.16 & 0.946 & 69.42 \\
\hline \multicolumn{12}{|c|}{ Treatment $0.5 \mathrm{mM}$ of RBBR at $333 \mathrm{~K}$, CHX $0.5 \mathrm{mM}$} \\
\hline 323 & 3.23 & 0.960 & 9.84 & 101.62 & 2.88 & 0.990 & 13.2 & 75.75 & 2.77 & 0.968 & 550.66 \\
\hline
\end{tabular}




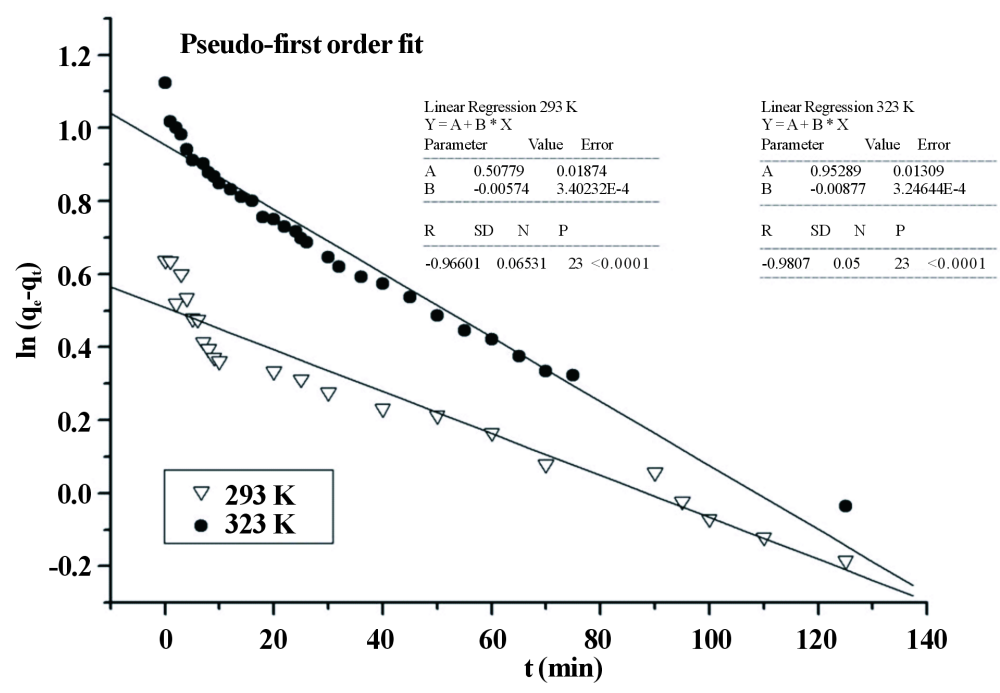

Figure 12. Pseudo-first order model fit of data from time-sorption isotherms of adsorption of $0.5 \mathrm{mM}$ CHX over Nylon 6.6 dyed with $0.5 \mathrm{mM}$ of RBBR at $323 \mathrm{~K}$, as function of the temperature.

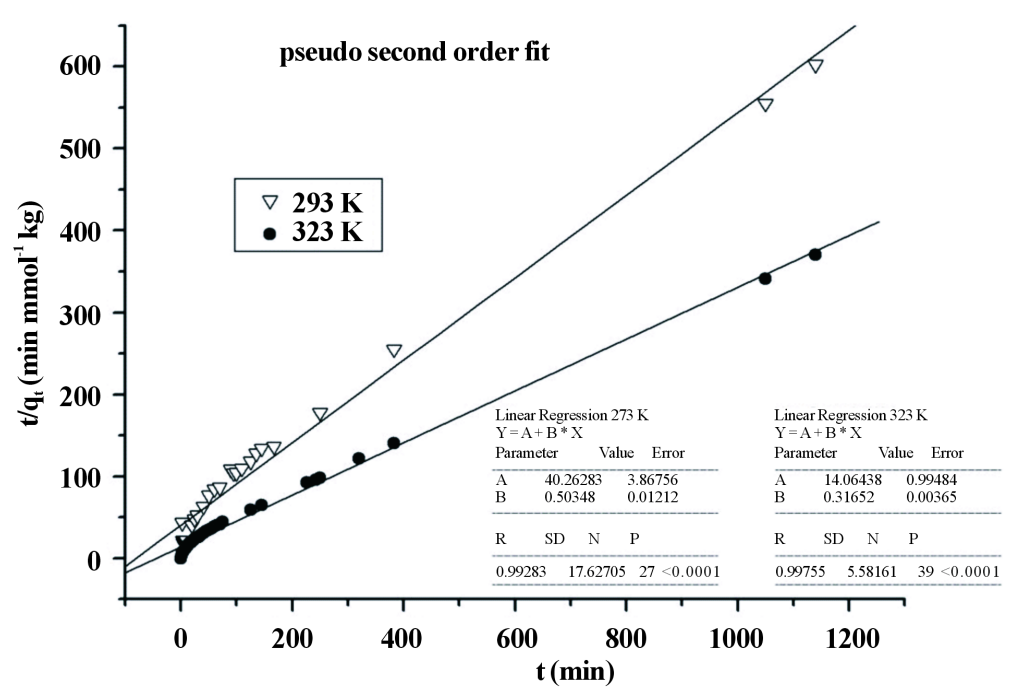

Figure 13. Pseduo-second order model fit of data from time-sorption isotherms of adsorption of $0.5 \mathrm{mM}$ CHX over Nylon 6.6 dyed with $0.5 \mathrm{mM}$ of RBBR at $323 \mathrm{~K}$, as function of the temperature.

order model, while sorption of CHX fits better to pseudo-second order model, and seems to be quicker process.

According to the obtained results, chemical interaction between vinyl-sulfone group of Remazol Brilliant Blue and the amine groups of Polyamide fiber, followed by electrostatic interactions between the guanine groups of the CHX and the sulfonate groups of the dye, must be considered in order to explain the adsorption process.

Further experiments will be presented in part II, with FTIR, zeta potential and surface energy components results of both systems, Nylon 6.6/RBBR and Nylon 6.6-RBBR/CHX, to give insight of the possible interactions that are taken place in fiber surface.

We want to express in this section that there are many possibilities of increasing the amount of RBBR uptaken by Nylon and therefore the number of molecules adsorbed by the fiber, changing initial conditions of $\mathrm{pH}$, ionic strength and increasing temperature. Because of the importance of $\mathrm{CHX}$ as a general antiseptic, this study would be very interesting because of its applicability. 


\section{Acknowledgements}

The authors of the present research would like to express their gratitude to DENTAID S.A. for providing us with Digluconate of Chlorhexidine used in this project, and especially to Ph.D. Mercé Sala for the information supplied for this project.

\section{References}

[1] Richeldorf, H.R. (2003) The Role of Ring-Ring Equilibrium in Thermodynamically Controlled Polycondensations. Macromolecular Symposia, 199, 15-22. http://dx.doi.org/10.1002/masy.200350902

[2] Viers, B.D. (1999) Polymer Data Handbook. Oxford University Press, Inc., Oxford, 189.

[3] Kamel, M.M., Hanna, H.L., El-Shishtawy, R.M. and Ahmed, N.S. (2001).Improving Nylon Dyeability by Using Redox System, Advances in Polymer Technology. Advances in Polymer Technology, 20, 237-247. http://dx.doi.org/10.1002/adv.1019

[4] Brandrup, J. and Immergut, E.H. (1989) Polymer Handbook. Wiley and Sons, New York.

[5] Peters, R.H. (1995) Textile Chemistry, Vol III. Elsevier Scientific Publishing Company, New York, 149-172.

[6] Chen, L., Bromberg, L., Hatton, T.A. and Rutledge, G.C. (2008) Electrospun Cellulose Acetate Fibers Containing Chlorhexidine as a Bactericid. Polymer, 49, 1266-1275. http://dx.doi.org/10.1016/j.polymer.2008.01.003

[7] Giménez-Martín, E., López-Andrade, M., Ontiveros-Ortega, A. and Espinosa-Jiménez, M. (2009) Adsorption of Chlorhexidine onto Cellulosic Fibers. Cellulose, 16, 467-479. http://dx.doi.org/10.1007/s10570-009-9281-5

[8] Morton, P. (1996) Oral Hygiene Products and Practice, Products Components: Therapeutic Agents. Marcel Dekker Inc., New York, 219-329.

[9] Gael, M., Patterson, S.S., Miller, C.H. and Newton, C.W. (2005) The Effect of Chlorhexidine Gluconate Irrigation on the Root Canal Flora of Freshly Extracted Necrotic Teeth, Oral Surgery, Oral Medicine. Oral Pathology, 53, 518-523.

[10] Soleimani, G.A. and Tylor, J.A. (2006) Dyeing of Nylon with Reactive Dyes. Part 1. The Effect of Changes in Dye Structure on the Dyeing of Nylon with Reactive Dyes. Dyes and Pigments, 68, 109-117. http://dx.doi.org/10.1016/j.dyepig.2005.01.014

[11] Dai, M. (1994) The Effect of Zeta Potential of Activate Carbon on the Adsorption of Dyes from Aqueous Solution. Journal of Colloid and Interface Science, 164, 223-228. http://dx.doi.org/10.1006/jcis.1994.1160

[12] Espinosa-Jiménez, M., Giménez-Martín, E. and Ontiveros-Ortega, A. (1997) Adsorption of N-Cetylpyridinium Chloride on Leacril Fibers: Kinetic and Thermodynamics. Textile Research Journal, 67, 677-683.

[13] Giménez-Martí, E., Ontiveros-Ortega, A., Espinosa-Jiménez, M. and Perea-Carpio, R. (2007) Electrokinetic Effect and Surface Free Energy Behavior in the Adsorption Process of a Reactive Dye onto Leacril Pretreated with Polyethyleneimine Iion. Journal of Colloid and Interface Science, 311, 394-399. http://dx.doi.org/10.1016/j.jcis.2007.03.020

[14] Ramos-Tejada, M.M., Ontiveros-Ortega, A., Giménez-Martín, E., Espionosa-Jiménez, M. and Molina-Díaz, A. (2006) Effect of Polyethyleneimine Ion on the Sorption of a Reactive Dye onto Leacril Fabric: Electrokinetic Properties and Surface Free Energy of the System. .Journal of Colloid and Interface Science, 297, 317-321. http://dx.doi.org/10.1016/j.jcis.2005.09.065

[15] Giménez-Martín, E. and Espinosa-Jiménez, M. (2005) Influence of Tannic Acid in Leacril/Rhodamine B System: Thermodynamics Aspects. Colloids and Surfaces, 270-271, 93-101. http://dx.doi.org/10.1016/j.colsurfa.2005.05.047

[16] Langmuir, I. (1918) The Adsorption of Gases on Plane Surface of Glass, Mica and Platinum. Journal of the American Chemical Society, 40, 1361-1402. http://dx.doi.org/10.1021/ja02242a004

[17] Espinosa-Jiménez, M., Padilla-Weigand, R., Ontiveros-Ortega, A., Perea-Carpio, R., Ramos-Tejada, M.M. and Chibowski, E. (2002) Investigation of the Polyamide 6.6 Dyeing with Acid Blue 45. Part. II. Journal Adhesion Science Technology, 16, 303-316. http://dx.doi.org/10.1163/156856102317295504

[18] Langergren, S. (1898) Zur Theorie der Sogenannten Adsorption Gelöster Stoffe-Kungliga Svenska Vetenskapsakademiens. Handlingar, 24, 1-39.

[19] Ho, Y.S. and McKay, G. (1998) Kinetic Models for the Sorption of Dye from Aqueous Solution by Wood. Process Safety and Environmental Protection, 76, 183-191.

[20] Faibrother, F. and Mastin, H. (1924) CCCXII-Studies in Electro-Endosmosis, Part 1. Journal of the Chemical Society, 75, 2318.

[21] Soleimani, G.A. and Tylor, J.A. (2006) Dyeing of Nylon with Reactive Dyes. Part 1. The Effect of Changes in Dye Structure on the Dyeing of Nylon with Reactive Dyes. Dyes and Pigments, 68, 109-117. http://dx.doi.org/10.1016/j.dyepig.2005.01.014 
[22] Özacar, M. and Sengil, I.A. (2003) Adsorption of Reactive Dyes on Calcined Alunite from Aqueus Solution. Journal of Hazardous Materials, B98, 211-224. http://dx.doi.org/10.1016/S0304-3894(02)00358-8

[23] Ho, Y.S. and McKay, G. (1998) Sorption of Dye from Aqueous Solution by Peat. Chemical Engineering Journal, 70, 115-124. http://dx.doi.org/10.1016/S0923-0467(98)00076-1 